\title{
Prevalence and control of risk factors in patients after acute coronary events
}

Coronary heart disease is the leading cause of hospital deaths in Sri Lanka [1]. The objective for patients with coronary heart disease is to reduce the risk of further coronary events. There is clear evidence that risk factor modification will help to achieve this objective [2], but studies in the United Kingdom [3] and Europe [2] have shown that the control of risk factors after a coronary event is often inadequate. Little data is available on the control and prevalence of risk factors in Sri Lankan patients. The purpose of our study was to assess the control of risk factors, use of appropriate medications in secondary prevention, advice given on secondary prevention and screening of first degree relatives for risk factors among patients after acute coronary events.

Patients with a history of myocardial infarction or unstable angina within the past 3 to 12 months attending medical wards and clinics at Sri Jayewardenepura General Hospital from August to December 2002 were included in this study. Data was collected using an intervieweradministered questionnaire. Results of biochemical tests were obtained from the patients' medical records.

We examined whether the patients had achieved the goals recommended by guidelines for secondary prevention of coronary events drawn up by the Joint European Societies [4,5].They were, to stop smoking, make healthy food choices, and become physically active; to achieve a body mass index (BMI) less than $25 \mathrm{~kg} / \mathrm{m}^{2}$, achieve a blood pressure below 140/90 $\mathrm{mmHg}$, a total serum cholesterol level below $5 \mathrm{mmol} / \mathrm{L}$, and LDL cholesterol concentration below $3 \mathrm{mmol} / \mathrm{L}$. We studied a total of 143 patients (men 83). The sample consisted of patients aged from 34 to 80 years. A past history of myocardial infarction was present in $63 \%$, and the rest had unstable angina.

Blood pressure control had not achieved the target in $25.9 \%$ of the patients. Glycaemic control was poor in $27.3 \%$. The total cholesterol was more than $5 \mathrm{mmol} / \mathrm{L}$ in $61.6 \%$, and LDL cholesterol was raised above $3 \mathrm{mmol} / \mathrm{L}$, in $77.6 \%$. The body mass index was above $25 \mathrm{~kg} / \mathrm{m}^{2}$ in
$30.1 \%$. The $75.5 \%$ of patients were not exercising at all. The recommended target of brisk walking $3 \mathrm{~km}$ three times weekly was achieved only in $11.4 \%$. Consumption of a high fat diet was noted in $22.8 \%$ and $5.2 \%$ of patients continued to smoke. The reported use of beta blockers was $53.8 \%$, ACE inhibitors $86 \%$, aspirin $90.9 \%$ and lipid lowering drugs $56.6 \%$.

Advice regarding the need to reduce the intake of fatty foods had not been given in $24.5 \%$ of patients. None of the patients had been told the importance of a regular exercise schedule. Only $45.5 \%$ had been advised to exercise. A $55.2 \%$ had not been told the importance of controlling hypertension and diabetes. Only $1.4 \%$ of patients had screened their first degree relatives for risk factors. The level of advice given to the patients on life style modification by the health care team was clearly inadequate. The use of drugs in secondary prevention is satisfactory, especially of aspirin and beta-blockers. In general, our study showed that patients' compliance with regard to drug therapy is more satisfactory than compliance to non-therapeutic measures. Introduction of cardiac rehabilitation clinics would enable better and focused attention, to be given for secondary prevention in patients after coronary events.

\section{References}

1. Annual Health Bulletin, Ministry of Health, Sri Lanka 2000.

2. David A Wood, EUROASPIRE I and II Group. Clinical reality of coronary prevention guidelines: a comparison of EUROASPIRE I and II in nine countries. Lancet 2001; 357: 995-1001

3. Bowker TJ, Clayton TC, Ingham J, McLennan NR, Hobson HL, et al. A British Cardiac Society survey of the potential for the secondary prevention of coronary disease: ASPIRE ( Action on Secondary Prevention through Intervention to Reduce Events). Heart 1996; 75: 334-42 
4. Pyorala K, De Backer G, Graham I, Poole-Wilson PA, Wood D. Prevention of coronary heart disease in clinical practice. Recommendations of the Task Force of the European Society of Cardiology, European Atherosclerosis Society and European Society of Hypertension. European Heart Journal 1994; 15: 1300-31
5. Second Joint Task Force of European and other Societies. Prevention of coronary heart disease in clinical practice. Recommendations of the Second Joint Task Force of European and other Societies on Coronary Prevention. European Heart Journal 1998; 19: 1434-503.

Harsha W Ediriweera, Sunera M Fernando (Intern Medical Officers), and CIW Jayasundera (Physician), Sri Jayewardenepura General Hospital (Teaching), Nugegoda; Senior Lecturer in Medicine, Faculty of Medicine, Colombo 8. Correspondence: H W E, Tel: + 94112585 274, e-mail: <harshae@dynanet.lk> (Competing interests: none declared). Received 13 August 2003 and revised version accepted 16 March 2004. 